\title{
Book review: Human Transit: How Clearer Thinking about Public Transit Can Enrich Our Communities and Our Lives, by Jarrett Walker
}

\author{
Kari Edison Watkins \\ Georgia Institute of Technology ${ }^{a}$
}

\author{
Human transit: How clearer thinking about public transit can enrich our communities and our lives \\ Jarrett Walker \\ Island Press, 2012 \\ ISBN: 9781597269728
}

Those who work in public transportation are often stuck defending transit as it could be rather than transit as it is. In many U.S. cities, it is hard for a middle-class or wealthy American to imagine transit as a mode that is freeing and spontaneous. Imagine for a minute a transit system that allows mobility such that you can walk a short distance, easily hop on a vehicle, travel relatively unimpeded for much of your trip, seamlessly connect to a new vehicle to travel a short distance, where you arrive at the doorstep of your destination. In the few situations where transit works this well, it is easy to suddenly see how this type of travel could be better than having to drag a 4,000 pound object along and find a place to put it everywhere you want to go. However, the inherent efficiencies of traveling collectively are often overrun by decades of development, policies, and decisions that have interfered with transit as it should be. It is therein that we have a need for Jarrett Walker's new book.

Human Transit is a back-to-basics look at the foundations of transit planning, service design, and operations. Walker relies on very simple concepts brought out in a simple manner, so much so that it seems unnecessary for such a text to exist. Unfortunately, as evidenced by our inability to provide transit as it should be in so many cases, such a text must be desperately needed.

Walker begins the book with a definition of public transit and its role in providing personal mobility, giving context to the points to come. He then continues with what amounts to the transit rider manifesto, "our seven demands" of public transportation (p. 24): "It takes me where I want to go; It takes me when I want to go; It is a good use of my time; It is a good

a kari.watkins@ce.gatech.edu use of my money; It respects me in the level of safety, comfort, and amenity it provides; I can trust it; (and) It gives me freedom to change my plans." In a key diagram of the book, he ties these seven demands to the elements of useful service: stops, connectivity, frequency, span, speed or delay, fare, civility, reliability, simplicity, and presentation. The rest of the book is organized around explaining these elements in more detail.

In subsequent chapters, Walker often comes back to what he calls the "plumber's questions," four major questions that are deliberate choices between two competing points of view about transit service. He proposes that anyone involved in planning transit is answering these questions whether they know it or not; and agencies are better served by making deliberate choices about these questions rather than haphazardly creating service that leans one way or the other. These four questions come down to:

1. Ridership or coverage?

2. Connections or direct service?

3. Peak or base service?

4. Exclusive rights-of-way or mixed traffic?

Some of the answers may seem obvious unless the reader has been involved in transit planning for as long as Walker. However, in delving deeper into each of the issues, he presents fantastic arguments with simple illustrations to explain the effects of each question on transit service and thereby the riders who are being served. Because of their limited budgets, few agencies have the time and resources to divide the customer experience and trip into elements as done in Human Transit. 
However, this analysis is essential to gaining and maintaining greater ridership.

The four major questions specifically deal with the key issues regarding frequency, connectivity, span, and speed or delay. However, the questions also cover stops, fares, reliability, and simplicity. The question of ridership or coverage deals with an agency's focus on providing high-frequency service in transit-supportive corridors versus providing some service to all areas regardless of cost per rider. Frequency is repeatedly brought out as a key variable of rider experience, with Walker quite reasonably equating frequency (headways of 15 minutes or less) to the freedom of true mobility. However, as described in the book, a doubling of frequency equates to a nearly doubling of operating cost. Ridership versus coverage also addresses stop coverage, as express or rapid services will focus on speed for the bulk of riders by consolidating stops rather than many stops for easy access to all.

Another major focus of the book is on connections versus direct service. Walker points out that the simplicity of connections in many cases allows more frequent service. As a person traveling with children, I tend to shy away from connections, because of the difficulty of getting on and off the transit vehicle. I think Walker's emphasis of connections also leaves out the tendency of many transit riders to make use of their time (reading, working, surfing the web) while traveling, which can be impeded by connections. However, his example of direct service versus connective option (pp. 150-152) powerfully illustrates the rider time savings that comes with more frequent service available by using connections. I tend to agree with him that our current travel demand models shy away from connections by assuming "transfer penalties" that may be much too aggressive in situations where connections are short in duration and seamless in execution, as seen more often abroad.

The third question of peak or base service refers to the provision of service that focuses on the morning and afternoon peak periods or service that focuses on all-day service with a reliable frequency and a longer span. Finally, exclusive rightsof-way or mixed traffic is about the priority that transit is given over other vehicles, which can come at a high infrastructure cost, but is logical when person mobility is valued over vehicle mobility. Bringing all four questions together, Walker posits that transit-intensive cities focus on high-ridership, allday, connective systems running on extensive segments of exclusive right-of-way.

Except for a cursory overview, Walker does not cover civility and presentation. He leaves Demand \#5 - "Respects me in level of safety, comfort and amenity" to draw from the work of others. However, this respect or civility is the downfall of services that are perceived to be "only for poor people," an attitude that can lead to ridership loss in the best-planned systems and degrade transit services due to low ridership in corridors that should be successful. Similarly, Demand \#6 - "I can trust it" is not explored enough in the book. Walker ties trust to frequency and reliability, but I would just as closely tie it to the element presentation. The information age allows us to present traveler information in new, exciting, and much more useful ways. Riders are now able to trust transit in ways that were previously not possible due to the current advances in providing better traveler information, including real-time arrivals, individualized service alert information, residential location choice tools and spontaneous trip planning tools. I would therefore add that successful transit-intensive cities need an equal focus on becoming information-intensive cities.

The reader will notice that none of the elements of useful service or the four major questions refer to choice of technology. In my years in the industry, I have often seen the choice of technology (BRT, LRT, heavy rail, monorail) take over public debate at the expense of service quality. "If we only had more $<$ insert mode here >, it would be easy to get around this city." As Walker eloquently points out (pp. 6 and 216), the technology is far less important than determining the market transit should serve and how to serve that market through proper transit geometry. The technology question must follow the other four major questions.

Overall, Walker brings out several important points often forgotten in the public dialogue. This is less of a book for experienced transit planners than an introduction to transit for the public and those who work in fields that impact transit service (roadway design, urban development, travel demand forecasting, traffic operations, etc.) about the issues underlying the provision of good transit. For the former, it provides examples that can be used by advocates to explain a key aspect of transit planning as they deliberate over a particular project or plan. For the latter, it serves as a concise go-to with important points about how geometry, development, and service demands impact transit operations. For all, Human Transit serves to explain how transit can work to provide mobility and transportation freedom. 